\title{
Electrochemical Recognition and Electrochemical Oxidation of Mesalazine Drug at PMA Modified Glassy Carbon Electrode
}

\author{
B Sreenatha Gupta, Madhusudhan Rao Vallabhaneni* \\ Department of Chemical Engineering, Vignan's Foundation for Science, Technology and Research, Vadlamudi, Guntur, Andhra Pradesh, INDIA.
}

\begin{abstract}
Background: Electrochemistry was the foremost subdivision of the chemistry its interred correlated to the entire other chemistries. Primarily it can settle on the nature of compound reactions by physically depends on the applying extent of electricity. The magnitude container is agreed away in connecting the optimistic and negative electrodes at the being there of analytic nearby in solution medium. Thus the electrochemistry is essentially depended on the reaction of chemical changes are by the persuade current of applying, on this perception the electricity is on the inside associated to the chemical type which are in attendance in the chemical compounds. These genus are sensitive to the functionalised electric value of potentials, and it was seen in varying of chemical reactions. In that basis, the changing of reactions is extensive in electrochemical reactions. Methods: In this Cyclic Voltammetry experimental method, crucial principal subsequent, instrumentation, and chemical changing noticing potentiostat of the electrochemical cell and recording apparatus are studied. The working electrodes are glassy carbon electrode was used for the harvest of this research work. How the glassy carbon electrode is useful to bring good results from using analytes. The procedures for doing a modification with modifiers on the surface of the electrode are clearly discussed. Results: A quick-tempered and miniature responsive analytical advance became evolved for the electrochemical oxidation of Mesalazine (MSZ) the procedure of electro ionic deposited modified PMA altered glassy carbon electrode (MGCE). The distorted electrode specify electrocatalytic attention
\end{abstract}

in the bearing of the oxidation of MSZ drug in $0.2 \mathrm{M}$ phosphate buffer solution (PBS) of $\mathrm{pH} 7.4$ with the assist of using cyclic voltammetric (CV) technique. The restrict of detection develop into calculated to be $79.50 \mathrm{nM}$ at misused electrode. The impacts of experiment charge observe shows evidence of an adsorption deal with electrode phenomenon. The altered electrode might be used as an analytical apparatus for the enthusiasm MSZ drug in pharmaceutical formulations. Conclusion: The planned electrode deposited PMA MGCE grows to be engaged for the electro-oxidation and stamina of an imperative drug MSZ at physiological $\mathrm{pH}$ by revenue of the use of CV modus operandi. The discovery perimeter grows to be calculated to be 79.50nM on behalf of MSZ with the method of CV.

Key words: Cyclic Voltammetry (CV), Phosphomolybdic acid (PMA), Masalazine (MSZ), Modified glassy carbon electrode (MGCE), Electrode lonic Deposited.

Correspondence

Dr. V. Madhusudhan Rao, FRSC,

Rector \& Dean, Department of Chemical Engineering, Vignan's Foundation for Science, Technology and Research, Vadlamudi-522213, Guntur, Andhra Pradesh, INDIA.

Email id: budidampad1959@gmail.com

DOI: $10.5530 /$ ijpi.2021.4.70

\section{INTRODUCTION}

The Mesalazine (mesalmine, 5-amino-2-hydroxy benzoic acid) was an amino salicylate antagonistic provocative prescription of mostly worn intended for the medicine of ulcerative colitis, bowel disease, and contaminated rectum and crohn's disease. It makes available safeguard towards the perfection of colorectal most cancers in patient distress commencing inflammatory bowel disease..$^{1-3}$ The function of Mesalazine (MSZ) be to wedge the developed of prostaglandins and leukotrienes. It besides restrain of bacterial peptide-brought on, expected executioner portable bustle, inhibition of cyclo oxygenase and lipoxygenase alleyway and mutilation of neutrophil chemo taxis, adenosine-brought on emission. ${ }^{4-6}$ Medicines are unpredictably fascinated from the diminutive intestine even as managed orally and consequently, a changed- begin dosage formality is premeditated to transport drug inside the incurable ileum and colon. Invented narrative survey found out that, there are a not many analytical techniques used for the strength of mind of MSZ in pharmaceutical preparations and organic samples the use of spectrophotometer. ${ }^{7,8}$ Chemiluminesence, Fluorescence, Ultraperformance liquid chromatography were moreover been accounted. ${ }^{9-14}$ Among the entire above declared strategies, the improvement of most recent analytical manners used for the resolve of Mesalazine drug be of luminous materials are contained by the recent period. For the reason of that the smooth procedure of operational, prompt and perfect possessions by low price, electro analytical methods are far and wide assumed. ${ }^{15-18}$ This work of ability describes the enlargement of an effortless sensor for voltammetric method of the directly, sensitive and simplicity of preparation pro the resolve of MSZ at an inorganic compound of phosphomolybdic acid (PMA) ionic ally deposited on the surface of the Glassy Carbon Electrode (GCE) has been anticipated. PMA complex molecule with inorganic metal and acid functional groups which have been present with a hydrophilic head ending similar to intellect with water of one side. ${ }^{19-23}$ Accordingly, at stumpy concentrations, immobilized of modified active molecules on the surface electrode. Adsorption of Ionic surfactant on the electrode constructs with charged, surfactant of cationic gives it positive charged and anionic surfactants formulate the atrocious exciting on electrode surface. Electrodes are going to charging investigation influence the oxidation means near cost relocateing charge in electrochemical dimensions. Electrode indicated special effects that electrochemical retort of scrutinized implement were outstandingly superior within the existence of surfactant. The electrodes contained surfactant modified is assumed formerly. ${ }^{24-28}$

To the superlative inspection of literature made to known that, here may be denial organizer at the MSZ electrochemical oxidation at PMA modified electrode ionically deposited glassy carbon electrode. The intent of the present work is to amplify a sensitive electroanalytical come 
near for the determination of MSZ at glassy carbon electrode modified (MGCE) with PMA. Finally, this comes close to has reimbursement including extreme reproducibility, sensitivity, fast retort, and low cost formulations of pharmaceutical and apposite detection limit of Mesalazine.

\section{MATERIALS AND METHODS}

\section{Instrumentation}

The experiments of electrochemical are conceded out the use of model $\mathrm{CHI}-660 \mathrm{c}$ (CH Instrument-660 electrochemical terminal). A predictable three electrode system happen to be engaged in an electrochemical cell through a saturated calomel electrode (SCE) as a reference, a platinum counter electrode and glassy carbon electrode or PMA electro chemically ionic deposited glassy carbon electrode as a working electrode. The entire voltammograms have been verification at an ambient temperature of $25 \pm 0.2^{\circ} \mathrm{C}$. The consequent oxidation capacity of analyte becomes recorded as contrasting to SCE.

\section{Chemicals and Reagents}

Mesalazine (MSZ) (MW=153.135 g/mol, 99.9\%) and phosphomolybdic acid (PMA) were attained from Himedia Chemicals Pvt Ltd. The solutions of stock were $25 \times 10^{-4} \mathrm{M} \mathrm{MSZ}$ and $25 \times 10^{-4}$ of PMA was primed in $0.1 \mathrm{M}$ perchloric acid and distilled water correspondingly. Phosphate buffer solution (PBS) of indistinguishable strength of ionic become organized $(0.2 \mathrm{M})$ with the assist of mixing proper fraction of $\mathrm{NaH}_{2} \mathrm{PO}_{4}$ and $\mathrm{NaHPO}_{4}$. The glassy carbon electrode (GCE) was polished using 0.3 and $0.5 \mu \alpha-\mathrm{Al}_{2} \mathrm{O}_{3}$ slurry on a polishing cloth proceeding to every experiment. Later than polishing and the electrode became extremely rinsed well with double distilled water. Awaiting a shiny reproduce similar to exterior is observed.

\section{RESULTS}

\section{Establishment of PMA electro ionic deposited modified glassy carbon electrode}

Cyclic voltammetry $(\mathrm{CV})$ is a prevailing, and expedient procedure to electro ionic deposited PMA based totally on the base of solid working electrode. ${ }^{18}$ The electro ionic deposited modified PMA on the surface of GCE altered into proficient with the support of consecutive brocading of bare glassy carbon electrode (BGCE) in an electrochemical cell containing 1.0mM of PMA in $0.2 \mathrm{M}$ PBS of $\mathrm{pH} 7.4$ as a selection of electrolyte. In support of the electro ionic deposited method, the facility window of -1.0 to $+1.2 \mathrm{~V}$ twisted into chosen with the scan accuse of $0.1 \mathrm{~V}^{\mathrm{s}-}$ for 40 cycles as showed in Figure 1, Figure 2. The thickness will become higher the modifier consequences in decrease inside the electrocatalytic diversion of the modified electrode. Therefore, 20 a couple of cycles or twenty segments had been choosing as an optimum. ${ }^{15}$ Later, the electro ionic deposited distorted glassy carbon electrode (MGCE) altered into sluiced thoroughly several times through double distilled water and used to Mesalazine (MSZ) intended for determination. Scheme 1 representing the probable electro ionic deposited mechanism of PMA on the surface of GCE was depicted in.

\section{The PMA MGCE electro deposited electrochemical characterization}

The stock solution of freshly setter $1 \mathrm{mM} \mathrm{K}_{4}\left[\mathrm{Fe}(\mathrm{CN})_{6}\right]$ during $1 \mathrm{M} \mathrm{KCl}$ be positioned during an electrochemical chamber. The Figure 3 established the cyclic voltammograms (CV's) witnessed, and meant in favour of the potassium ferrocyanide oxidation explore on each BGCE (dashed line) and electro deposited PMA MGCE (solid line) amid scan rate $0.1 \mathrm{Vs}^{-1}$. The redox peak current low reaction be attained at BGCE, though inside

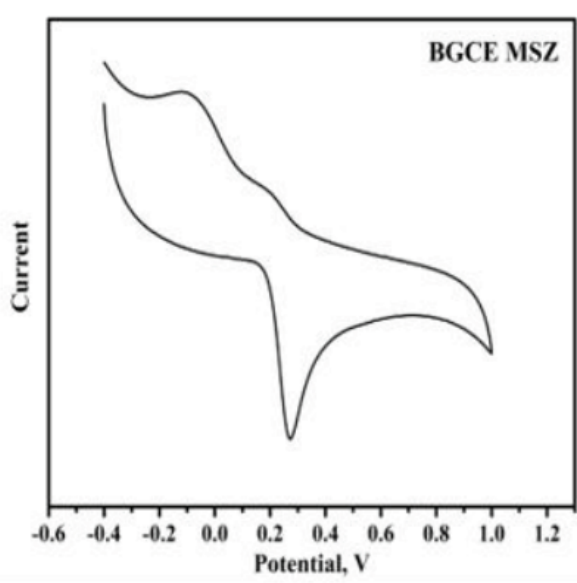

Figure 1: A cyclic voltammogram MSZ at bare glassy carbon electrode of 0.2M PBS at $\mathrm{pH} 7.5$.

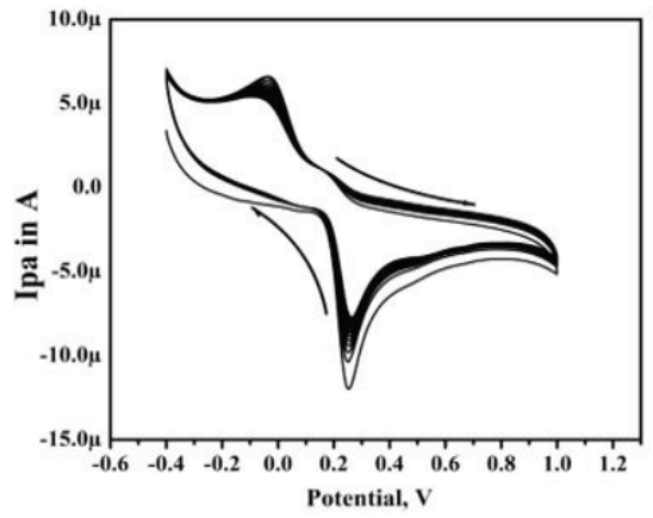

Figure 2: Cyclic voltammograms of preparation of electrode deposited PMA MGCE. The 0.2M PBS resolution of pH 7.4 in $1 \mathrm{mM} \mathrm{PMA}$ at 40 cycles with scan rate $0.1 \mathrm{Vs}^{-1}$.

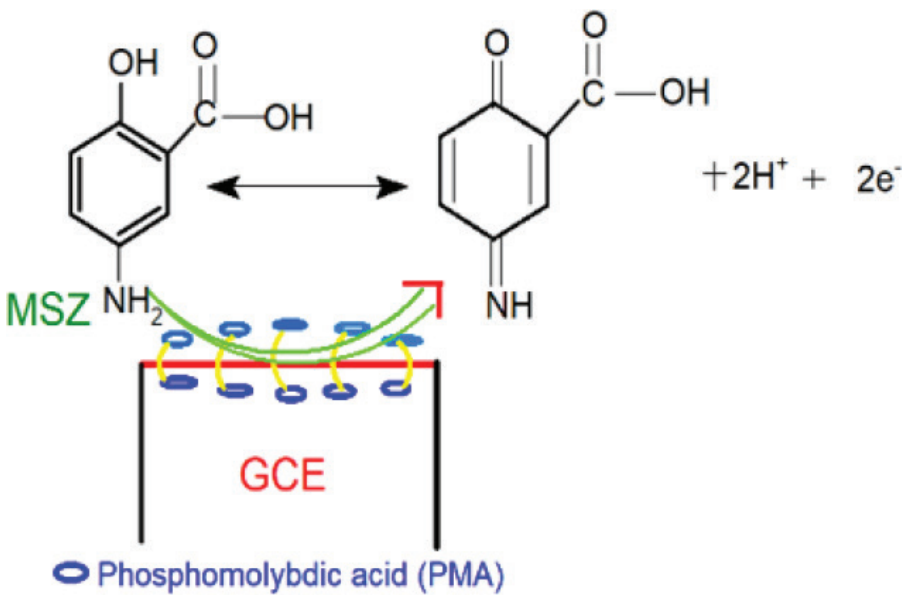

Scheme 1: Probable mechanism of electrode deposited PMA on the surface of glassy carbon electrode.

the alike impossible to tell apart stipulation electrodeposited PMA MGCE demonstrated stagnant growth within the peak current redox potentials, for the reason that of the more rapidly kinetics of electron transfer on the surface of the electrode. A stepped ahead response of 


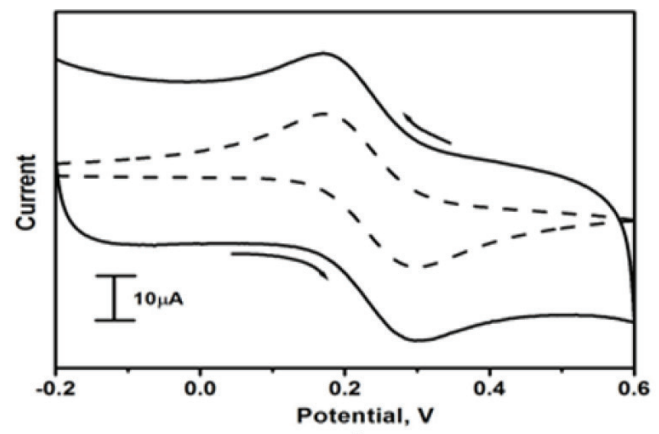

Figure 3: $\mathrm{CV}$ s of $1 \mathrm{mM}$ potassium ferrocyanide at BGCE (dashed line) Electrode deposited PMA MGCE (solid line) at scan rate of $0.1 \mathrm{Vs}^{-1}$.

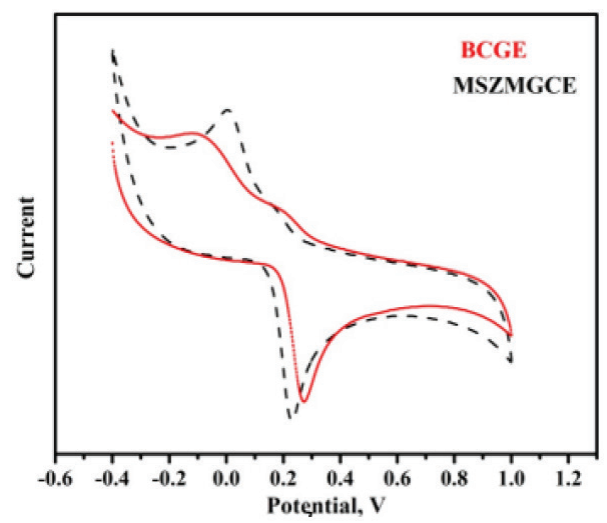

Figure 4: cyclic voltammograms of $1 \mathrm{mM}$ and PBS at BGCE (dashed line) and electrode deposited PMA MGCE (solid line) at scan rate of $0.1 \mathrm{Vs}^{-1}$.

voltammetric was placed at electrodeposited PMA MGCE. This last part results concerned the exterior assets of the transformed electrode have been noticeably changed and moreover the endings prove to the commotion of electrocatalytic at the electrodeposited PMA MGCE. This last part result concerned the property of surface altered electrode has been noticeably distorted and the endings attest that the activity of electrocatalytic at the electrodeposited PMA MGCE. The totality to be had plane situate in support of retort of variety in respond container be predicted with the way of using Randles-Sevcik equation (1)..$^{18,29}$

$$
\text { Ip }=2.69 \times 10^{5} n^{3 / 2} \mathrm{AD}^{1 / 2} C_{0} u^{1 / 2}
$$

Where, Ip is the peak current in A. $\mathrm{n}$ is the number of electrons exchanged, $\mathrm{C}_{0}$ is the concentration of the electroactive species $\left.(\mathrm{mol} \mathrm{cm})^{-3}\right), A$ is the electroactive surface area $\left(\mathrm{cm}^{-2}\right), \mathrm{D}$ is the diffusion-coefficient $\left(\mathrm{cm}^{2} \mathrm{~s}^{-1}\right)$, and is the scan rate $\left(\mathrm{Vs}^{-1}\right)$. For electrode deposited PMA MGCE the surface area of electroactive is maximum $\left(0.0359 \mathrm{~cm}^{2}\right)$ as balanced among BGCE $\left(0.0298 \mathrm{~cm}^{2}\right)$.

\section{Electrode deposited PMA MGCE MSZ at Electrochemical oxidation}

Figure 4 Illustrates the CV's confirmed intended in support of the oxidation of $0.1 \mathrm{mM} \mathrm{MSZ}$ at BGCE in $\mathrm{pH} 7.4$ of $0.2 \mathrm{M}$ PBS by way of the scan rate of $0.05 \mathrm{Vs}^{-1}$. On BGCE (dashed line) the MSZ definite an enormous voltammetric reply amid low signals of current and turn into positioned at $0.2715 \mathrm{~V}$ (vs. SCM). However, though the MSZ oxidation potential was twisted into placed at $0.2019 \mathrm{~V}$ at electrode ionic ally deposited PMA MGCE (solid line). The peak to peak severance $(\Delta \mathrm{Ep})$ linking potentials of redox at PMA MGCE were to a large extent fewer as contrasted to BGCE, signifying the rapid kinetics of electron transfer at the electrode modified. This minimization of in excess of oxidation facility and increment inside the modern reaction proves the activity of electrocatalytic with the fictitious electrode in the track of the realistic oxidation of MSZ. The MSZ mechanism of oxidation was twisted into confirmed in Scheme 2.

\section{The MSZ achieves at different scan rate on PMA MCPE}

In this constraint MSZ achieve of deviation inside the apply scan rate for $0.1 \mathrm{mM}$ of MSZ in $0.2 \mathrm{M}$ PBS of $\mathrm{pH} 7.5$ be converted into observed by means of cyclic voltammetric technique at electrode ionic ally deposited PMA MGCE as explained in Figure 5. The results of experimental attains at electrode deposited PMA MGCE explains and explosion in the elevation of redox currents with increase inside the carried-out scan rate inside the range 0.02 to $0.2 \mathrm{Vs}^{-1}$ and they're proportional to each other in line with Randles-Sevcik equation. The observations showed that there's a sensible affecting of anodic elevation potential (Epa) closer to magnificent portion and cathodic altitude potential $(\mathrm{Epc})$ to the negative side. In order to announce the electrode process, the graph of anodic peak current (Ipc) as opposed to scan rate $(v)$ and Ipa verses square root of scan rate $\left(v^{1 / 2}\right)$ have been plotted as shown in Figure 6 and Figure 7 respectively. A peak linearity $\left(r^{2}=0.99542\right)$ twisted into originate for $v$ and Ipa. Which authenticates the adsorption prohibited observable fact on the surface of electrode. ${ }^{18,29,30}$

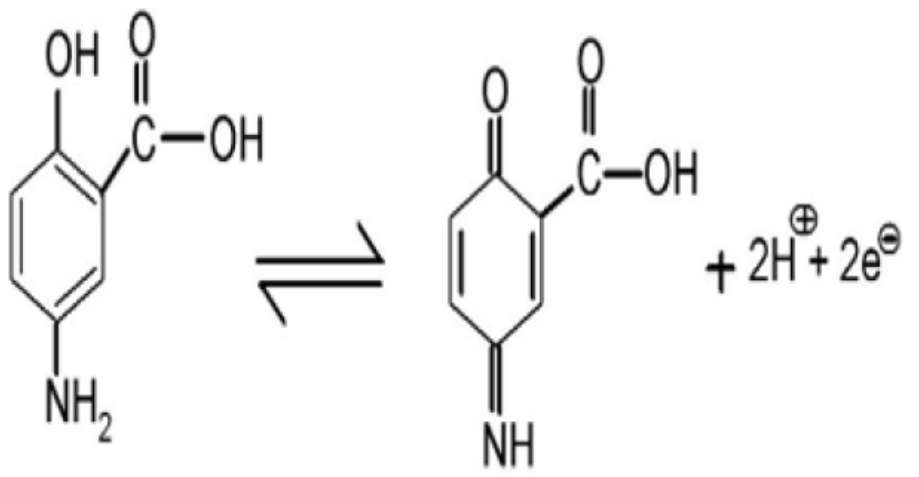

Scheme 2: Oxidation mechanism of Mesalazine.

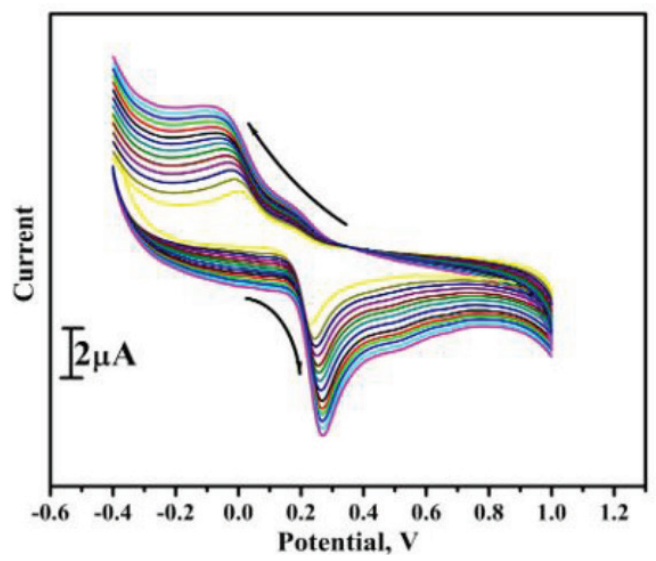

Figure 5: Cyclic voltammograms $0.1 \mathrm{mM}$ PBS solution of $\mathrm{pH} 7.5$ at electrode deposited PMA MGCE at diverse scan rate $\left(0.02 \mathrm{Vs}^{-1}\right.$ to $\left.0.2 \mathrm{Vs}^{-1}\right)$. 


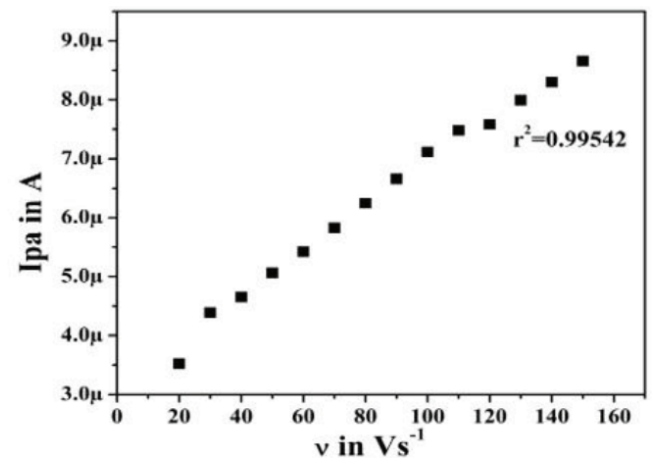

Figure 6: Graph of anodic peak current versus scan rate.

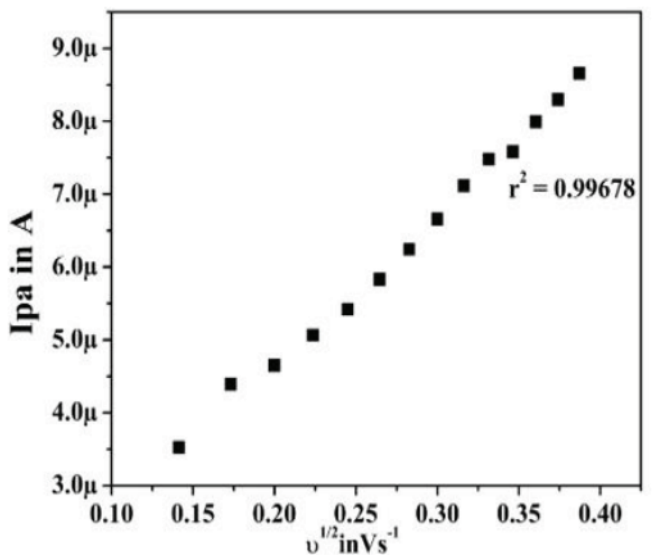

Figure 7: Graph of anodic peak current versus square root of scan rate.

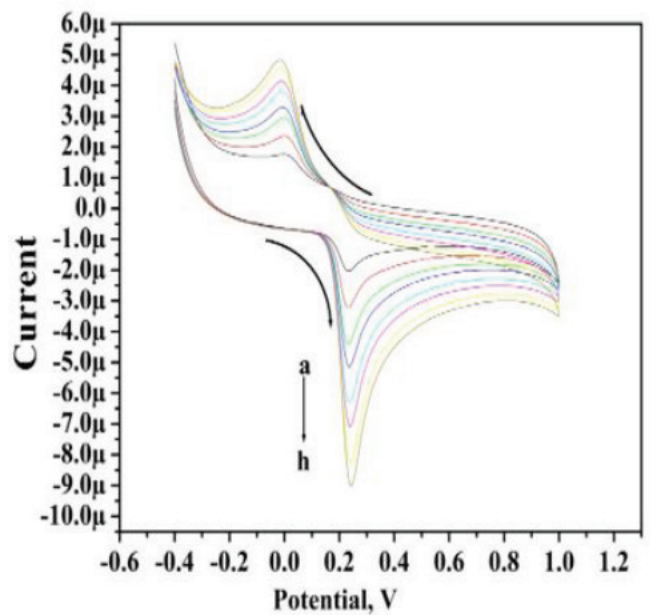

Figure 8: Cyclic voltammograms of MSZ in 0.2M PBS solution of $\mathrm{pH} 7.4$ at Electrode deposited PMA MGCE at scan rate of 0.05Vs-1 with different concentration (a-h; $0.02 \mu \mathrm{M}$ to $0.16 \mathrm{mM}$ ).

\section{The effect of concentration of MSZ}

In this parameter the electrocatalytic oxidation of MSZ misrepresented into consummate by using a mixture of its awareness at electrode deposited PMA Modified Glassy Carbon Electrode. In Figure 8 illustrated, during growing the attentiveness of MSZ commencing $0.02 \mu \mathrm{M}$ to $0.16 \mathrm{mM}$ the Ipc and Ipa is passing resting on rising with moving Epa in a minute before a slighter quantity superior and Epc

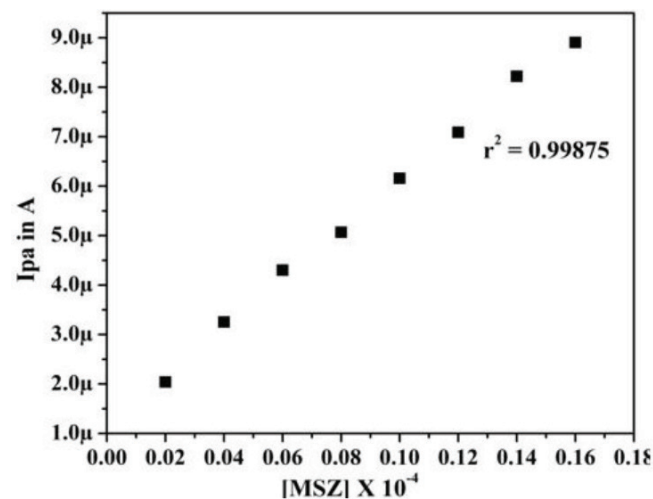

Figure 9: Graph of anodic peak current versus concentration of MSZ.

nearer to slightest negative elevation. The graph of MSZ Concentration vs Ipa be plotted as illustratating in the Figure 9, it providing almost immediately stripe with pleasing linearity. The equation of linear regression preserve subsist expressed as $\operatorname{Ipa}(A)=2.040 \times 10^{-6}$ to $8.9054 \times 10^{-6}\left(r^{2}=0.99875\right)$. The restrictions of detection (LOD) turn into calculated with the equation (2). ${ }^{18,23}$

$$
L O D=3 S / M
$$

Where, $\mathrm{M}$ is the slope of the calibration graph, $\mathrm{S}$ is the standard deviation of six blank-solution measurements. ${ }^{4}$ The LOD twisted into calculated inside the decline alertness diversity for MSZ and was exposed to be 79.50nM. The anticipated technique reveal decline recognition control than individual statement as made to known in a Table $1 ., 18,31-33$

\section{The effect of $\mathrm{pH}$ value on the purpose of MSZ at PMA MGCE}

In this conforming the effect of $\mathrm{pH}$ the $\mathrm{PBS}$ has an enormous donation at the MSZ electrocatalytic oxidation at the electrode deposited PMA MGCE by means of affecting mutually progressive peak and potentials. The impact of $\mathrm{PBS} \mathrm{pH}$ rate on the resolution of MSZ at electrode deposited PMA MGCE was warily evaluated in a greatly broader $\mathrm{pH}$ range of 5.5-8.0. The Figure 10 illustrated cyclic voltammograms recorded for 0.065 to $0.1880 \mathrm{~V}$ of MSZ at electrode deposited PMA MGCE. The oxidation revolves into hygienic at essential media. The Figure 11 illustrate anodic elevation potential (Epa) Vs graph of $\mathrm{pH}$ in fact pointed out that the Epa mainly with by linearly at the $\mathrm{pH}$ value within the ranges of 5.5-8.0 among a slope of $0.065 \mathrm{~V} / \mathrm{pH}$ $\left(r_{2}=0.80366\right)$ while definite into Figure 10. This suggests and close with an involvement of equal number of protons and electrons contained by the redox mechanism. The invariable with the former reports in literature..$^{18,21}$

\section{DISCUSSION}

A quick-tempered and miniature responsive analytical advance became evolved for the electrochemical oxidation of Mesalazine (MSZ) the procedure of electro ionic deposited modified PMA altered glassy carbon electrode (MGCE). The distorted electrode specify electrocatalytic attention in the bearing of the oxidation of MSZ drug in $0.2 \mathrm{M}$ phosphate buffer solution (PBS) of $\mathrm{pH} 7.4$ with the assist of using cyclic voltammetric $(\mathrm{CV})$ technique. The results of different scan rate experimental attains at electrode deposited PMA MGCE explains and explosion in the elevation of redox currents with increase inside the carried-out scan rate inside the range 0.02 to $0.2 \mathrm{Vs}^{-1}$ and they're proportional to each other in line with Randles-Sevcik equation. The 
Table 1: Comparison of limit of detection (LOD) with different modified electrodes and Electrode deposited PMA MGCE.

\begin{tabular}{|c|c|c|c|c|}
\hline Technique & Working Electrode & Concentration range $(\mathrm{M})$ & Limit of detection & Reference \\
\hline SWV & Pencil graphite electrodes & $9.8 \times 10^{-7}-7.3 \times 10^{-5}$ & $2.1 \times 10^{-8}$ & 31 \\
\hline AdLSV & CNT/PPY doped by 1,5-napthalenedisulfonic acid & $1.0 \times 10^{-8}-1.0 \times 10^{-6}$ & $3.0 \times 10^{-9}$ & 32 \\
\hline Sona LSV & GCE & $1.0 \times 10^{-6}-5.7 \times 10^{-5}$ & $3.0 \times 10^{-7}$ & 33 \\
\hline DPV & GCE & $2.0 \times 10^{-6}-1.0 \times 10^{-4}$ & $8.2 \times 10^{-7}$ & 4 \\
\hline $\mathrm{CV}$ & Poly (glutamic acid) MGCE & $50.0 \times 10^{-6}-0.5 \times 10^{-3}$ & $23.94 \times 10^{-9}$ & 18 \\
\hline $\mathrm{CV}$ & PMA MGCE & $2.04 \times 10^{-6}-8.905 \times 10^{-6}$ & $79.50 \times 10^{-7}$ & This work \\
\hline
\end{tabular}

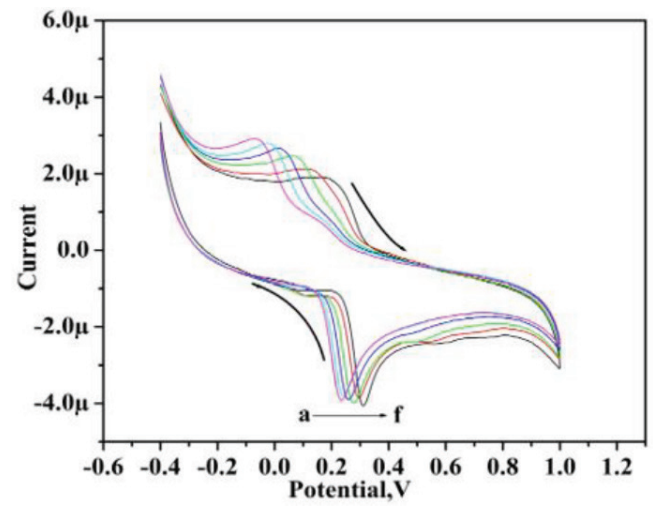

Figure 10: Cyclic voltammograms of the electrode ionic deposited PMA MGCE in 0.2M PBS solution at different pH (a-f: 5.5 to 8.0) at scan rate of $0.05 \mathrm{Vs}^{-1}$.

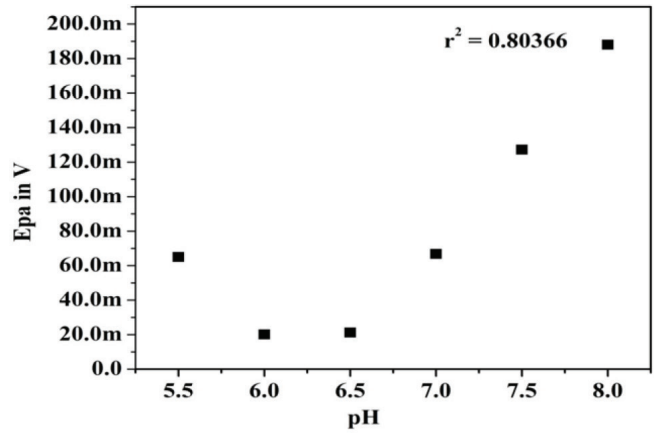

Figure 11: The effect of peak potential response of $0.4 \times 10-4 \mathrm{M} \mathrm{MSZ}$ in $0.2 \mathrm{M}$ PBS of different $\mathrm{pH}$.

restrict of detection develop into calculated to be $79.50 \mathrm{nM}$ at distorted electrode. The impacts of experiment charge observe shows evidence of an adsorption deal with electrode phenomenon. The effect of $\mathrm{pH}$ suggests and close illustrate anodic elevation potential (Epa) Vs graph of $\mathrm{pH}$ in fact pointed out that the Epa mainly with by linearly at the $\mathrm{pH}$ value within the ranges of 5.5-8.0 among a slope of $0.065 \mathrm{~V} / \mathrm{pH}$ $\left(\mathrm{r}^{2}=0.80366\right)$ while definite with an involvement of equal number of protons and electrons contained by the redox mechanism. The altered electrode might be used as an analytical apparatus for the enthusiasm MSZ drug in pharmaceutical formulations.

\section{CONCLUSION}

In instructing to add to the concert of bare glassy carbon electrode it bowed keen on personalized by way of glassy carbon electrode ionically deposited on the surface of the electrode by means of cyclic voltammetric technique. The planned electrode deposited PMA MGCE grows to be engaged for the electro-oxidation and stamina of an imperative drug MSZ at physiological $\mathrm{pH}$ by revenue of the use of $\mathrm{CV}$ modus operandi. The discovery perimeter grows to be calculated to be $79.50 \mathrm{nM}$ on behalf of MSZ with the method of CV. The made-up showed electrode improbable reproducibility, sensitivity, and antifouling property en route for the perseverance of MSZ.

\section{ACKNOWLEDGEMENT}

I thank my guide Dr. Madhusudhan Rao Vallabhaneni for his expertise and assistance throughout all aspects of my study and for his help in writing the manuscript.

\section{CONFLICT OF INTEREST}

The authors declare that there is no conflict of interest.

\section{REFERENCES}

1. Yi H, Li C. Voltammetric determination of ciprofloxacin based on the enhancement effect of cetyltrimethylammonium bromide (CTAB) at carbon paste electrode. Russ J Electrochem. 2007;43(12):1377-81. doi: 10.1134/ S1023193507120075.

2. Llorent-Martínez EJ, Ortega-Barrales P, Fernández de Córdova ML, Ruiz-Medina A. Development of an automated chemiluminescence flow-through sensor for the determination of 5-aminosalicylic acid in pharmaceuticals: A comparative study between sequential and multicommutated flow techniques. Anal Bioanal Chem. 2009;394(3):845-53. doi: 10.1007/s00216-009-2757-1.

3. Sahoo NK, Sahu M, Srinivasa Rao PS, Ghosh G. Validation of stability indicating RP-HPLC method for the estimation of mesalamine in bulk and tablet dosage form. Pharm Method. 2013;4(2):56-61. doi: 10.1016/j.phme.2013.12.003.

4. Nigovic B, Šimunic B. Determination of 5-aminosalicylic acid in pharmaceutical formulation by differential pulse voltammetry. J Pharm Biomed Anal. 2003;31(1):169-74. doi: 10.1016/S0731-7085(02)00469-7.

5. Uliana CV, Yamanaka H, Garbellini GS, Salazar-Banda GRS. Determination of 5-aminosalicylic acid in pharmaceutical formulations by square wave voltammetry at pencil graphite electrodes. Quim Nova. 2010;33(4):964-7. doi: 10.1590/S0100-40422010000400036.

6. Kim S, Wang N, Li Y, He X. Electrochemical determination of mesalazine by using graphene oxide coated with a molecularly imprinted sol-gel. Anal Methods. 2016;8(43):7780-88. doi: 10.1039/C6AY02243J.

7. Garmonov SY, Nguyen ZC, Mingazetdinov IF, Yusupova LM, Shitova NS, Ismailova RN, et al. Spectrophotometric determination of mesalazine in urine for assessing the acetylation phenotype in vivo in humans. Pharm Chem J. 2012;45(12):757-60. doi: 10.1007/s11094-012-0719-y.

8. Laghari MGH, Darwis Y, Memon AH. New Spectrophotometric Methods for the Determination of p-Aminosalicylic Acid in Tablets. Trop J Pharm Res. 2014;13(7):1133-39. doi: 10.4314/tjpr.v13i7.18.

9. Gotti R, Pomponio R, Bertucci C, Cavrini V. Determination of 5-aminosalicylic acid related impurities by micellar electrokinetic chromatography with an ion-pair reagent. J Chromatogr A. 2001;916(1-2):175-83. doi: 10.1016/s00219673(00)01097-9, PMID 11382289.

10. Yu Garmonov S, Nguyen ZC, Mingazetdinov IF, Yusupova LM, Shitova NS, Ismailova RN, et al. Spectrophotometry determination of mesalazine in urine for assessing the acetylation phenotype in vivo in humans. J Chem. 2012;45:757.

11. Abdolmohammad-Zadeh $H$, Kohansal $S$. Determination of mesalamine by spectrofluorometry in human serum after solid-phase extraction with $\mathrm{Ni}-\mathrm{Al}$ layered double hydroxide as a nanosorbent. J Braz Chem Soc. 2012;23(3):473-81. doi: 10.1590/S0103-50532012000300014.

12. Nandipati S, Reddy VK, Uba S. A validated ultraperformance liquid chromatography method for assay determination of mesalamine. PharmSci. 
2013;5:312-16

13. Sivarami Reddy K, Ramachandra B, Naidu NVS. Development and validation of HPLC assay method for determination mesalamine in bulk drug and tablet formulation. Int J Sci Eng Res. 2014;2:52.

14. Pinto J, Spínola V, Llorent-Martínez EJ, Fernández-de Córdova ML, Molina-García L, Castilho PC. Polyphenolic profile and antioxidant activities of Madeiran elderberry (Sambucus lanceolata) as affected by simulated in vitro digestion. Food Res Int. 2017:100(3):404-10. doi: 10.1016/j.foodres.2017.03.044. PMID 28964363.

15. Ganesh PS, Swamy BEK. Simultaneous electroanalysis of norepinephrine, ascorbic acid and uric acid using poly (glutamic acid) modified carbon paste electrode. J Electroanal Chem. 2015;752:17-24. doi: 10.1016/j. jelechem.2015.06.002

16. Ganesh PS, Kumara Swamy BEK. Simultaneous electroanalysis of hydroquinone and catechol at poly(brilliant blue) modified carbon paste electrode: A voltammetric study. J Electroanal Chem. 2015;756:193-200. doi: 10.1016/j. jelechem.2015.08.027.

17. Ganesh PS, Swamy BEK. Voltammetric resolution of catechol and hydroquinone at eosin Y film modified carbon paste electrode. J Mol Liq. 2016;220(208):208-15. doi: 10.1016/j.molliq.2016.04.078.

18. Kumar AA, RaniTS, Ganesh PS, Kumara Swamy BE. Electrochemical Oxidation of Masalazine Drug at poly (glutamic acid) Modified Glassy Carbon Electrode. Anal Bio Anal Electro Chem. 2017;3:328-39.

19. Hatchett DW, Josowicz M. Composites of intrinsically conducting polymers as sensing nanomaterials. Chem Rev. 2008;108(2):746-69. doi: 10.1021/cr068112h, PMID 18171087.

20. Abbar JC, Nandibewoor ST. Voltammetric oxidation and determination of atorvastatin based on the enhancement effect of cetyltrimethyl ammonium bromide at a carbon paste electrode. Colloids Surf B Biointerfaces. 2013;106:158-64. doi: 10.1016/j.colsurfb.2013.01.045, PMID 23434706.

21. Buddanavar AT, Gowda JI, Nandibewoor ST. Voltammetric behavior of isoniazid and its electroanalytical determination at carbon nanotubes CTAB modified glassy carbon electrode. Anal Bioanal Electrochem. 2016;8(3):329-44

22. Teradale AB, Lamani SD, Das SN. Up growth effect of cetyltrimethyl ammonium bromide with carbon paste electrode for the electrochemical determination of allopurinol and its biological activities. Anal Bioanal Electrochem. 2016;8:814-29.

23. Gowda JI, Mallappa M, Nandibewoor ST. CTAB functionalized multiwalled carbon Nano tube composite modified electrode for the determination of 6-mercaptopurine. Sens Bio Sens Res. 2017;12:1-7.

24. Fernández L, Carrero $\mathrm{H}$. Electrochemical evaluation of ferrocene carboxylic acids confined on surfactant-clay modified glassy carbon electrodes: oxidation of ascorbic acid and uric acid. Electrochim Acta. 2005;50(5):1233-40. doi: 10.1016/j.electacta.2004.08.016.

25. Yuan S, Chen W, Hu S. Fabrication of TiO2 nanoparticles/surfactant polymer complex film on glassy carbon electrode and its application to sensing trace dopamine. Mater Sci Eng C. 2005;25(4):479-85. doi: 10.1016/j. msec.2004.12.004

26. Fernández L, Borrás $\mathrm{C}$, Carrero $\mathrm{H}$. Electrochemical behavior of phenol in alkaline media at hydrotalcite-like clay/anionic surfactants/glassy carbon modified electrode. Electrochimica Acta. 2006;52(3):872-84. doi: 10.1016/j. electacta.2006.06.021.

27. Vittal R, Gomathi $H$, Kim KJ. Beneficial role of surfactants in electrochemistry and in the modification of electrodes. Adv Colloid Interface Sci. 2006;119(1):55-68. doi: 10.1016/j.cis.2005.09.004, PMID 16325752

28. Manisankar P, Selvanathan G, Vedhi C. Determination of pesticides using heteropolyacid montmorillonite clay-modified electrode with surfactant. Talanta. 2006;68(3):686-92. doi: 10.1016/j.talanta.2005.05.021, PMID 18970376.

29. Ganesh PS, Swamy BEK. Voltammetric investigation of catechol and hydroquinone at Triton X-100 Modified Carbon Paste Electrode. Anal Bioanal Electrochem. 2016;8(5):615

30. Rekha, Kumara Swamy BE, Poly GPS. (Amoxicillin) modified carbon paste electrode for the determination of dopamine: A cyclic voltammetric study. J Biosens Bioelectron. 2016;8(2):184-92

31. Beckett EL, Lawrence NS, Evans RG, Davis J, Compton RG. Sono electro chemically enhanced determination of 5-aminosalicylic acid. Talanta. 2001;54(5):871-77. doi: 10.1016/s0039-9140(01)00337-x, PMID 18968310.

32. Akkaya A, Altug C, Pazarlioglu NK, Dinckaya E. Determination of 5-Aminosalicylic Acid by Catalase-Peroxidase Based Biosensor. Electroanalysis. 2009;21(16):1805-10. doi: 10.1002/elan.200904606.

33. Uliana CV, Yamanaka H, Garbellini GS, Salazar-Banda GRS. Determination of 5-aminosalicylic acid in pharmaceutical formulations by square wave voltammetry at pencil graphite electrodes. Quim Nova. 2010;33(4):964-7. doi: $10.1590 /$ S0100-40422010000400036.

Article History: Submission Date : 09-09-2021; Revised Date : 05-10-2021; Acceptance Date : 28-10-2021.

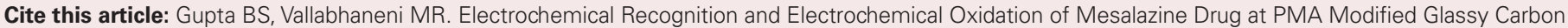
Electrode. Int. J. Pharm. Investigation. 2021;11(4):389-94. 